\title{
Association of a serotonin transporter gene (SLC6A4) 5-HTTLPR polymorphism with body mass index categories but not type 2 diabetes mellitus in Mexicans
}

\author{
Valeria Peralta-Leal ${ }^{1, *}$, Evelia Leal-Ugarte ${ }^{1}$, Juan P. Meza-Espinoza ${ }^{1}$, Ingrid P. Dávalos-Rodríguez ${ }^{2,3}$, \\ Anabel Bocanegra-Alonso ${ }^{4}$, Rosa I. Acosta-González ${ }^{4}$, Enrique Gonzales ${ }^{5}$, Saraswathy Nair ${ }^{5}$ \\ and Jorge Durán-González ${ }^{5, *}$ \\ ${ }^{1}$ Facultad de Medicina e Ingeniería en Sistemas Computacionales, Departamento de Genética Aplicada \\ a la Medicina, Universidad Autónoma de Tamaulipas, H. Matamoros Tamaulipas, México. \\ ${ }^{2}$ Instituto Mexicano del Seguro Social, División de Genética, Guadalajara, Jalisco, México. \\ ${ }^{3}$ Doctorado en Genética Humana, Departamento de Biología Molecular y Genómica, \\ Universidad de Guadalajara, Guadalajara, Jalisco, México. \\ ${ }^{4}$ Unidad Académica Multidisciplinaria Reynosa-Aztlán, Departamento de Análisis Clínicos, \\ Universidad Autónoma de Tamaulipas, México. \\ ${ }^{5}$ University of Texas at Brownsville, Department of Biological Sciences and Center of Biomedical Studies, \\ Brownsville, TX, USA.
}

\begin{abstract}
The serotonergic system has been hypothesized to contribute to the biological susceptibility to type 2 diabetes mellitus (T2DM) and body-mass index (BMI) categories. We investigate a possible association of 5-HTTLPR polymorphism ( $L$ and $S$ alleles) in the promoter region of the serotonin transporter gene (SLC6A4) with the development of T2DM and/or higher BMI by analyzing a sample of 138 individuals diagnosed with T2DM and 172 unrelated controls from the Mexican general population. In the total sample genotypes were distributed according to HardyWeinberg equilibrium, and S allele frequency was 0.58 . There was no statistical association between 5-HTTLPR polymorphism and the development of T2DM in this Mexican population sample $(p=0.12)$. Nevertheless, logistic regression analysis of the $\mathrm{L}$ allele and increased $\mathrm{BMI}$ disclosed an association, after adjusting for age, sex and T2DM $(\mathrm{p}=0.02$, OR $1.74,95 \% \mathrm{Cl}: 1.079-2.808)$.
\end{abstract}

Key words: SLC6A4 gene, 5-HTTLPR polymorphism, type 2 diabetes mellitus, body mass index.

Received: June 17, 2011; Accepted: March 22, 2012.

Over the last three decades, the rates of overweight, obesity, and type 2 diabetes mellitus (T2DM) have increased worldwide (Ogden et al., 2006; Fuemmeler et al., 2009 ;). Specifically, and with a rising prevalence of $10.6 \%$, Mexico is among the top 10 countries with the highest number of diabetic individuals (6.1 million) (Rull et al., 2005; Gonzalez-Villalpando et al., 2010) where it has also been reported that the combined prevalence of overweight and obesity is 63\% among Mexicans (Arroyo et al., 2000; Fernald et al., 2004). Obesity and T2DM frequently co-occur, indicating that these conditions share common pathological mechanisms, including complex interactions

Send correspondence to Valeria Peralta-Leal. Facultad de Medicina e Ingeniería en Sistemas Computacionales, Avenida Sendero Nacional km 3, C.P. 87380. H Matamoros, Tamaulipas, México. E-Mail: valeriaperaltaleal@yahoo.com.mx.

*These authors contributed equally to this paper. between genetic and environmental factors (Knowler et al., 1993). In the search for genetic factors that confer susceptibility to obesity and T2DM, several candidate genes have been identified (Prokopenko et al., 2008; Yang et al., 2007). Due to their function in the brain and gastrointestinal tract, genes of the serotonergic system are included among these. Serotonin (5-hydroxytryptamine or 5-HT) is involved in the regulation of energy balance through central modulation of the activity of various downstream neuropeptide systems, as well as autonomic pathways (Iordanidou et al., 2010). Some functional effects of 5-HT include mood control, urine storage, voiding, sleep regulation, body temperature, circadian functions, feeding behavior, body weight, and intestinal motility (Lesch et al., 1996; Ni and Watts, 2006; Sookoian et al., 2008). It is well established that 5-HT activity is regulated by the 5-HT transporter (5-HTT), whose functions include 5-HT re-uptake in 
serotonergic nerve terminals, thereby determining the magnitude and duration of postsynaptic response to 5-HT, and signaling quantity (Lesch and Mossner, 1998).

The human 5-HTT is encoded by the serotonin transporter gene (SLC6A4) on chromosome 17, at 17q11.217q12 (Lesch et al., 1996). Located at 1,400 bp upstream of the transcription start site of the gene, a functional polymorphism has been described, the SLC6A4-linked polymorphic region or 5-HTTLPR (Collier et al., 1996; Heils et al., 1996). This consists of two common alleles, i.e., a short (S) variant with 14 copies, and a long $(\mathrm{L})$ variant with 16 copies of a 44 bp repeat element (Lesch et al., 1996; Kraft et al., 2005). The S allele (SS or SL genotypes) is associated with lower SLC6A4 expression, thereby resulting in reduced 5-HT reuptake and release capability, whereas the L variant is associated with an almost threefold increase in gene transcription (Iordanidou et al., 2010). Association studies of 5-HTTLPR with glucose metabolism, changes in the body-mass index (BMI) and T2DM are relatively recent. In a longitudinal study of Japanese women, analysis of the association of SLC6A4 polymorphism with fasting blood glucose (FBG) levels indicated that the SS genotype plays a protective role, thereby improving FBG values (Yamakawa et al., 2005). Meanwhile, in one of the largest cohorts studied to date, involving, 1,584 unrelated individuals, a subsample of the US National Longitudinal Study of Adolescent Health, Fuemmeler et al. (2008) found that SS and SL 5-HTTLPR genotypes are significantly associated with a higher BMI, for men overall, and for Hispanic men and those of European ancestry, specifically. This association was further confirmed in South American population samples of adolescents and adults of European ancestry, in which the $\mathrm{S}$ allele was found to be a risk factor (Sookoian et al., 2007, 2008). So far, in only one study has reported the $\mathrm{S}$ allele as a risk factor for T2DM, in a Caucasian population from Greece, interestingly, the presence of the $\mathrm{S}$ allele was not found to be associated with increased BMI values (Iordanidou et al., 2010).

The aim of the present study was to investigate whether there was an association of the 5-HTTLPR polymorphism of the SLC6A4 gene with T2DM or BMI (as a measure of obesity) in a Mexican population sample.

A total of 138 unrelated subjects diagnosed with T2DM (42 males and 96 females) and 172 unrelated controls (48 males and 124 females) from Mexican general population were studied. All individuals were recruited at the Hospital "Secretaria de Salud, Hospital General de Reynosa, Dr. Jose Maria Cantu Garza" Tamaulipas, Mexico. Inclusion of subjects in the diabetic group was based on medical diagnosis, according to the criteria recommended by the WHO for T2DM (Deckers et al., 2006). Subjects with either diagnosis or a first-degree family history of type T2DM were excluded from the control sample. BMI was calculated as the ratio between weight and the square of the height $(\mathrm{kg} / \mathrm{m} 2)$. Subjects were also divided into over- weight/obese (BMI > 25) and non-obese $($ BMI < 25) groups. The study protocol for human experimentation was previously approved by the local ethics committee (PROMEP/103.5/08/3243). Informed consent was obtained from each subject before participation in the study.

Genomic DNA was isolated from peripheral blood for genotyping, according to Gustincich et al. (1991). Polymerase Chain Reaction (PCR) for 5-HTTLPR polymorphism genotyping was performed as previously described Cook et al. (1997), with minor modifications. The forward primer used was HTTp2A, 5'-TGAATGCCAGCACCTAACCC-3', and the reverse primer HTTp2B, 5'-TTCTGGTGCCACCTAGACGC-3'. The final amplicon product consisted of 406/450-bp fragments (S and L alleles, respectively). PCR was carried out in a total volume of $25 \mu \mathrm{L}$ containing $200 \mu \mathrm{M}$ of each dNTP (dATP, dCTP, and dTTP), $100 \mu \mathrm{M}$ of dGTP and 7-deazadGTP, 1 unit of Taq polymerase (High Fidelity; Invitrogen), $1.5 \mathrm{mM}$ of MgSO4, 5\% DMSO, and $10 \mathrm{mM}$ of Tris-HCl. Amplification was carried out in a Thermal Cycler C1000 System through 40 cycles consisting of $30 \mathrm{~s}$ at $95{ }^{\circ} \mathrm{C}, 30 \mathrm{~s}$ at $61{ }^{\circ} \mathrm{C}$, and $1 \mathrm{~min}$ at $71{ }^{\circ} \mathrm{C}$, followed by 10 min at $72{ }^{\circ} \mathrm{C}$. PCR products were separated by electrophoresis on a $6 \%$ polyacrylamide gel at $120 \mathrm{~V}$ for $3 \mathrm{~h}$. Bands were visualized using a silver nitrate staining protocol. Subjects were classified into three genotypes: individuals homozygous for the short allele SS, those heterozygous for the short and long allele LS, and those homozygous for the long allele LL.

Data are shown as means and \pm standard deviation (SD). Deviation from Hardy-Weinberg equilibrium was confirmed by $X^{2}$-test analysis of genotype distribution. The association between 5-HTTLPR and T2DM|BMI, as an obesity|overweight measure, was defined by logisticregression analysis, assuming an additive model. Considering gender, age and T2DM as the appropriate covariates, associations were adjusted accordingly. The odds ratios (ORs) with $95 \%$ confidence intervals (CIs) are presented in the tables with respect to the risk allele. A $P$ value of 0.05 was considered significant. Statistical analysis was performed using PLINK version 1.07 (Purcell et al., 2007), and SPSS version 17.0 (SPSS, Chicago, IL, USA). Quanto Software version 1.2.4 (Gauderman and Morrison, 2006) was used for calculating the power of the sample. On considering $10.6 \%$ diabetes prevalence among Mexican individuals (Rull et al., 2005), a frequency of $42 \%$ for the analyzed polymorphism and an additive genetic model, allowed to estimate that the sample size of the present study had an $80 \%$ power at an alpha of 0.05 to detect an effect size of 1.6 .

Gender distribution among the 310 participants was $71 \%$ females and $29 \%$ males. According to the WHO criteria for diagnosis, 138 individuals had T2DM (44.5\%), whereas 172 were non-diabetic (55.5\%). The distribution of BMI, according to WHO classification and differences 
between subgroups, are shown in Table 1. Genotype distribution of the SLC6A4 gene among the analyzed groups is shown in Table 2. 5-HTLPR polymorphism was found to be in Hardy-Weinberg equilibrium in the total sample $(p=0.24)$. Although logistic regression analysis indicated no statistically significant association of the 5-HTTLPR polymorphism with T2DM $(p=0.17)$, BMI was shown to be a discrete predictor of T2DM in the Mexican population (Table 3). This same association was found when BMI was analyzed as a continuous variable under the linear regression model ( $\mathrm{p}=0.03,1.874$ [0.1336-3.615]). The $\mathrm{L}$ allele was associated with overweight/obesity BMI values by logistic regression analysis $(\mathrm{p}=0.02 ; 1.74$ [1.079-2.808]) (Table 4), independent of age, gender or T2DM.

The high prevalence and increasing number of Mexicans suffering from obesity and T2DM represent a huge burden on healthcare (Mier et al., 2008; Gonzalez-Villalpando et al., 2010), whence the prime importance of identifying risk factors for susceptibility to these conditions. The Mexican population we investigated showed a statistical difference in age distribution between the diabetic and non-diabetic groups, as expected, since T2DM is a chronic condition increasing in prevalence, as the population ages. As previously shown (Iordanidou et al., 2010), our analysis confirmed BMI as a discrete predictor of T2DM. Although described in Caucasians (Iordanidou et al., 2010), in the
Table 3 - Logistic regression analysis of the association between T2DM and the L allele of the SLC6A4 5-HTTLPR polymorphism.

\begin{tabular}{lccc}
\hline Covariates & OR & $95 \% \mathrm{CI}$ & $\mathrm{p}$ \\
\hline L allele & 0.7375 & $(0.5022-1.083)$ & 0.12 \\
Age & 1.062 & $(1.041-1.084)$ & $<0.001^{*}$ \\
Gender & 0.8936 & $(0.5094-1.568)$ & 0.69 \\
BMI $\left(\mathrm{kg} / \mathrm{m}^{2}\right)$ & 1.048 & $(1.008-1.09)$ & $0.01^{*}$ \\
\hline
\end{tabular}

Model Adjusted by Age, Sex and BMI.

* = Statistically significant.

Table 4 - Logistic regression analysis of the association between overweight and the L allele of the SLC6A4 5-HTTLPR polymorphism.

\begin{tabular}{lccc}
\hline Covariates & OR & $95 \% \mathrm{CI}$ & $\mathrm{p}$ \\
\hline L allele & 1.74 & $(1.079-2.808)$ & $0.02^{*}$ \\
Age & 1.012 & $(0.9924-1.032)$ & 0.23 \\
Gender & 1.292 & $(0.6948-2.404)$ & 0.41 \\
T2DM & 2.415 & $(1.284-4.543)$ & $0.006^{*}$ \\
\hline
\end{tabular}

Model Adjusted by Age, Sex and T2DM.

$*=$ Statistically significant.

present Mexican population sample, no association between 5-HTTLPR polymorphism of the SLC6A4 gene and T2DM was detected. Nonetheless, frequency of the previ-

Table 1 - Characteristics of the analyzed groups.

\begin{tabular}{|c|c|c|c|c|c|c|}
\hline Phenotypes & Non-diabetic group $n=172$ & Diabetic group $n=138$ & $\mathrm{p}$ & $\mathrm{BMI}<25 \mathrm{n}=69$ & $\mathrm{BMI}>25 \mathrm{n}=217$ & $\mathrm{p}^{*}$ \\
\hline Age (Years) & $45 \pm 16.5$ & $54 \pm 10.8$ & $<0.001 *$ & $46 \pm 17.36$ & $50.40 \pm 13.55$ & 0.05 \\
\hline Gender (M/F) & $48(28 \%) / 124(72 \%)$ & $42(30 \%) / 96(70 \%)$ & & $21(30 \%) / 48(70 \%)$ & $60(27 \%) / 157(73 \%)$ & \\
\hline Presence of T2DM & & & & $31 \%$ & $52 \%$ & \\
\hline $\mathrm{BMI}>25$ & $69 \%$ & $84 \%$ & & & & \\
\hline Body weight (kg) & $70.06 \pm 16.40$ & $74.87 \pm 16.13$ & $0.003 *$ & $56.74 \pm 8.25$ & $77.89 \pm 14.33$ & $<0.001^{*}$ \\
\hline BMI $\left(\mathrm{kg} / \mathrm{m}^{2}\right)$ & $26.92 \pm 10.2$ & $28.6 \pm 6.8$ & 0.06 & $22.63 \pm 1.7$ & $31.12 \pm 4.6$ & $<0.001 *$ \\
\hline
\end{tabular}

Values are mean \pm SD

* = Statistically significant.

Table 2 - Genotype and allele frequencies of the SLC6A4 5-HTTLPR polymorphism in the analyzed groups.

\begin{tabular}{|c|c|c|c|c|c|c|}
\hline \multirow{2}{*}{$\begin{array}{l}\text { 5-HTTLPR } \\
\text { polymorphism }\end{array}$} & \multicolumn{6}{|c|}{ Phenotypes } \\
\hline & Non-Diabetic Group & Diabetic Group & Total & $\mathrm{BMI}<25$ & $\mathrm{BMI}>25$ & Total \\
\hline & n $(\%)$ & $\mathrm{n}(\%)$ & $\mathrm{n}(\%)$ & n $(\%)$ & $\mathrm{n}(\%)$ & n $(\%)$ \\
\hline \multicolumn{7}{|l|}{ Genotypes } \\
\hline LL & $33(20)$ & $16(12)$ & $49(16)$ & $7(11)$ & $37(18)$ & $44(16)$ \\
\hline LS & $88(51)$ & $74(53)$ & $162(52)$ & $35(50)$ & $118(54)$ & $153(53)$ \\
\hline SS & $51(29)$ & $48(35)$ & $99(32)$ & $27(39)$ & $62(28)$ & $89(31)$ \\
\hline \multicolumn{7}{|l|}{ Alleles } \\
\hline $\mathrm{L}$ & $154(45)$ & $106(39)$ & $260(42)$ & $49(36)$ & $192(45)$ & $241(42)$ \\
\hline $\mathrm{S}$ & $190(55)$ & $170(61)$ & $360(58)$ & $89(64)$ & $242(55)$ & $331(58)$ \\
\hline
\end{tabular}


ously reported T2DM risk allele S was higher. Increased frequencies of the $\mathrm{S}$ allele have already been reported in Native American, Japanese, Chinese and Korean populations the highest frequencies, even reaching $80 \%$ (Goldman et al., 2010). On analyzing BMI values, with adjustment of age, gender and T2DM as covariates, the role of T2DM as a predictor of obesity was clearly shown (Table 4). While Yamakawa et al. (2005) reported that the $\mathrm{S}$ allele was protective, as regards FBS levels, our results showed a direct association of the $\mathrm{L}$ allele with increased BMI, independent of age, gender or T2DM. These results differ from those reported by Sookoian et al. (2007, 2008), showing the S allele to be a risk factor for higher BMI among adolescent and adult men from Argentina, as is also shown by Fuemmeler et al. (2008) in Caucasian and Hispanic adolescents from the U.S.A. Nonetheless, all these studies are in agreement by pointing out that $S L C 6 A 4$ polymorphism is associated with BMI, and ethnicity may be a contributing factor towards the differences between our study and previous reports. From a functional perspective and through in vitro studies, it is assumed that the $\mathrm{L}$ allele is associated with relatively increased SLC6A4 transcription, thereby resulting in increased transporter levels and more rapid 5-HT uptake (Lesch et al., 1996; Greenberg et al., 1999), whence the inference that there may be a reduction in extracellular serotonin among LL homozygous carriers (Glenn, 2011). In contrast to the $\mathrm{L}$ allele, it has been shown that the $\mathrm{S}$ allele is associated with lower transcriptional activity and reduced 5-HT reuptake efficiency (Heils et al., 1996). Hence, it can be tentatively argued that patients with SS or SL genotypes have greater availability of $5-\mathrm{HT}$ at their central serotonergic synapses, thereby intensifying satiety and reducing food intake, and so inducing lower BMI and decreased fat mass (Monteleone et al., 2006). Interestingly, in animal models and humans, an increase in 5-HT levels leads to eating less, whereas a decrease in 5-HT activity precipitates compulsive or binge eating (Blundell, 1986).

Due to the relatively small number of subjects in this study, Type II error, through the lack of observed association between the analyzed polymorphism and T2DM, cannot be ruled out. Further analysis with a larger sample is warranted. Another limitation in this preliminary study was the paucity of additional phenotypes investigated, such as insulin and lipid levels, and other relevant clinical measurements. Since the Mexican population resulted from an admixture of Native Americans and Europeans (Spanish) with a smaller contribution from African groups, the probability of population stratification cannot be ruled out. Nevertheless, the information reported in this preliminary investigation is relevant, because of the high impact of obesity as a health problem in Mexico. In addition, the allele frequencies of SLC6A4 polymorphism determined in this population sample constitute a useful reference for genetic studies.

\section{Acknowledgments}

We thank the Secretaría de Educación Pública (SEP), Programa de Mejoramiento del Profesorado (PROMEP) for the support in the development of this research (UATPTC-119), official release letter number PROMEP/103.5/08/3243, and the $2^{\circ}$ apoyo institucional a proyectos de investigación de la Universidad Autónoma de Tamaulipas (UAT10-SAL-0407). We also thank Dr. Cesar Peralta Coronado for his valuable comments to the project.

\section{References}

Arroyo P, Loria A, Fernandez V, Flegal KM, Kuri-Morales P, Olaiz G and Tapia-Conyer R (2000) Prevalence of preobesity and obesity in urban adult Mexicans in comparison with other large surveys. Obes Res 8:179-185.

Blundell JE (1986) Serotonin manipulations and the structure of feeding behaviour. Appetite 7(Suppl):39-56.

Collier DA, Stober G, Li T, Heils A, Catalano M, Di BD, Arranz MJ, Murray RM, Vallada HP, Bengel D, et al. (1996) A novel functional polymorphism within the promoter of the serotonin transporter gene: Possible role in susceptibility to affective disorders. Mol Psychiatry 1:453-460.

Cook Jr EH, Courchesne R, Lord C, Cox NJ, Yan S, Lincoln A, Haas R, Courchesne E and Leventhal BL (1997) Evidence of linkage between the serotonin transporter and autistic disorder. Mol Psychiatry 2:247-250.

Deckers JG, Schellevis FG and Fleming DM (2006) WHO diagnostic criteria as a validation tool for the diagnosis of diabetes mellitus: A study in five European countries. Eur J Gen Pract 12:108-113.

Fernald LC, Gutierrez JP, Neufeld LM, Olaiz G, Bertozzi SM, Mietus-Snyder M and Gertler PJ (2004) High prevalence of obesity among the poor in Mexico. JAMA 291:2544-2545.

Fuemmeler BF, Agurs-Collins TD, McClernon FJ, Kollins SH, Kail ME, Bergen AW and Ashley-Koch AE (2008) Genes implicated in serotonergic and dopaminergic functioning predict BMI categories. Obesity 16:348-355.

Fuemmeler BF, Agurs-Collins T, McClernon FJ, Kollins SH, Garrett ME and Ashley-Koch AE (2009) Interactions between genotype and depressive symptoms on obesity. Behav Genet 39:296-305.

Glenn AL (2011) The other allele: Exploring the long allele of the serotonin transporter gene as a potential risk factor for psychopathy: A review of the parallels in findings. Neurosci Biobehav Rev 35:612-620.

Goldman N, Glei DA, Lin YH and Weinstein M (2010) The serotonin transporter polymorphism (5-HTTLPR): Allelic variation and links with depressive symptoms. Depress Anxiety 27:260-269.

Gonzalez-Villalpando C, Lopez-Ridaura R, Campuzano JC and Gonzalez-Villalpando ME (2010) The status of diabetes care in Mexican population: Are we making a difference? Results of the National Health and Nutrition Survey 2006. Salud Publica Mex 52:S36-S43.

Greenberg BD, Tolliver TJ, Huang SJ, Li Q, Bengel D and Murphy DL (1999) Genetic variation in the serotonin transporter promoter region affects serotonin uptake in human blood platelets. Am J Med Genet 88:83-87. 
Gustincich S, Manfioletti G, Del Sal G, Schneider C and Carninci P (1991) A fast method for high-quality genomic DNA extraction from whole human blood. Biotechniques 11:298300,302 .

Heils A, Teufel A, Petri S, Stober G, Riederer P, Bengel D and Lesch KP (1996) Allelic variation of human serotonin transporter gene expression. J Neurochem 66:2621-2624.

Iordanidou M, Tavridou A, Petridis I, Arvanitidis KI, Christakidis D, Vargemezis V and Manolopoulos VG (2010) The serotonin transporter promoter polymorphism (5-HTTLPR) is associated with type 2 diabetes. Clin Chim Acta 411:167-171.

Knowler WC, Saad MF, Pettitt DJ, Nelson RG and Bennett PH (1993) Determinants of diabetes mellitus in the Pima Indians. Diabetes Care 16:216-227.

Kraft JB, Slager SL, McGrath PJ and Hamilton SP (2005) Sequence analysis of the serotonin transporter and associations with antidepressant response. Biol Psychiatry 58:374-381.

Lesch KP, Bengel D, Heils A, Sabol SZ, Greenberg BD, Petri S, Benjamin J, Muller CR, Hamer DH and Murphy DL (1996) Association of anxiety-related traits with a polymorphism in the serotonin transporter gene regulatory region. Science 274:1527-1531.

Lesch KP and Mossner R (1998) Genetically driven variation in serotonin uptake: Is there a link to affective spectrum, neurodevelopmental, and neurodegenerative disorders? Biol Psychiatry 44:179-192.

Mier N, Bocanegra-Alonso A, Zhan D, Wang S, Stoltz SM, Acosta-Gonzalez RI and Zuniga MA (2008) Clinical depressive symptoms and diabetes in a binational border population. J Am Board Fam Med 21:223-233.

Monteleone P, Santonastaso P, Mauri M, Bellodi L, Erzegovesi S, Fuschino A, Favaro A, Rotondo A, Castaldo E and Maj M (2006) Investigation of the serotonin transporter regulatory region polymorphism in bulimia nervosa: Relationships to harm avoidance, nutritional parameters, and psychiatric comorbidity. Psychosom Med 68:99-103.

Ni W and Watts SW (2006) 5-hydroxytryptamine in the cardiovascular system: Focus on the serotonin transporter (SERT). Clin Exp Pharmacol Physiol 33:575-583.
Ogden CL, Carroll MD, Curtin LR, McDowell MA, Tabak CJ and Flegal KM (2006) Prevalence of overweight and obesity in the United States, 1999-2004. JAMA 295:1549-1555.

Prokopenko I, McCarthy MI and Lindgren CM (2008) Type 2 diabetes: New genes, new understanding. Trends Genet 24:613-621.

Purcell S, Neale B, Todd-Brown K, Thomas L, Ferreira MA, Bender D, Maller J, Sklar P, de Bakker PI, Daly MJ, et al. (2007) PLINK: A tool set for whole-genome association and population-based linkage analyses. Am J Hum Genet 81:559-575.

Rull JA, Aguilar-Salinas CA, Rojas R, Rios-Torres JM, GomezPerez FJ and Olaiz G (2005) Epidemiology of type 2 diabetes in Mexico. Arch Med Res 36:188-196.

Sookoian S, Gemma C, Garcia SI, Gianotti TF, Dieuzeide G, Roussos A, Tonietti M, Trifone L, Kanevsky D, Gonzalez CD, et al. (2007) Short allele of serotonin transporter gene promoter is a risk factor for obesity in adolescents. Obesity 15:271-276.

Sookoian S, Gianotti TF, Gemma C, Burgueno A and Pirola CJ (2008) Contribution of the functional 5-HTTLPR variant of the SLC6A4 gene to obesity risk in male adults. Obesity 16:488-491.

Yamakawa M, Fukushima A, Sakuma K, Yanagisawa Y and Kagawa Y (2005) Serotonin transporter polymorphisms affect human blood glucose control. Biochem Biophys Res Commun 334:1165-1171.

Yang W, Kelly T and He J (2007) Genetic epidemiology of obesity. Epidemiol Rev 29:49-61.

\section{Internet Resources}

Gauderman WJ and Morrison JM (2006) QUANTO 1.1: A computer program for power and sample size calculations for genetic-epidemiology studies. http://hydra.usc.edu/gxe (June 17, 2011).

Associate Editor: Angela M. Vianna-Morgante

License information: This is an open-access article distributed under the terms of the Creative Commons Attribution License, which permits unrestricted use, distribution, and reproduction in any medium, provided the original work is properly cited. 